Research Article

\title{
Assessment of patient's satisfaction regarding the service quality of a rural hospital of Burdwan district, West Bengal, India
}

\author{
Prosenjit Naskar*, Somnath Naskar, Sima Roy
}

Department of Community Medicine, Burdwan Medical College and Hospital, West Bengal, India

Received: 14 June 2016

Accepted: 04 July 2016

*Correspondence:

Dr. Prosenjit Naskar,

E-mail: prosenjit.703@gmail.com

Copyright: () the author(s), publisher and licensee Medip Academy. This is an open-access article distributed under the terms of the Creative Commons Attribution Non-Commercial License, which permits unrestricted non-commercial use, distribution, and reproduction in any medium, provided the original work is properly cited.

\begin{abstract}
Background: Patients satisfaction is the basis of quality healthcare services. To improve quality of healthcare it is most important to obtain feedback from patients. Patients' satisfaction or service quality mostly depends on patients' expectation. This study was conducted to identify some important areas where improvement can be done by knowing patients expectation, perception and their gaps.

Methods: A cross-sectional study was conducted among patients aged >18 years. Total 350 patients from OPD by consecutive sampling and 309 patients from IPD by complete enumeration was taken from a rural hospital of Burdwan district. A modified form of SERVQUAL questionnaires was used.

Results: Service quality gaps were identified across all the five dimensions as well as all the 22 items of the survey instrument (except one item). All those gaps were statistically significant (Except two items). It was identified that highest service quality gap exist against the item no. 8 (Provide its services at the time) for OPD and item no. 20 (Readiness for personal attention) for IPD services.

Conclusions: This study measured service quality of a hospital in the context of patients' perceptions and expectations and identified some areas of improvement while catering health services. The findings can help the healthcare provider to plan conceptually in improving health care delivery systems.
\end{abstract}

Keywords: Expectation, Perception, Service quality, SERVQUAL, Patients’ satisfaction

\section{INTRODUCTION}

Patient satisfaction and quality of service is a multidimensional aspect. To improve quality of health services it is most important to obtain feedback from the consumer be it patient or patient party. In every aspect satisfaction depends mostly on the expectation. So to measure quality of services in a hospital it is important to measure patients or patient party's expectation and perception and find out their knowledge so as to evaluate quality of services.

Quality in health services entails two dimensions: technical quality (outcome quality) and functional quality (process quality). Technical quality focuses on the accuracy of medical diagnoses and procedures whereas functional quality refers to the way in which health care services are delivered to patients. Because most of patients lack the required knowledge for evaluating the technical quality of the services, their evaluation of quality is based on the medical care process. ${ }^{1}$

It is very difficult to measure patients' satisfaction or quality of service as a whole or in every aspect, as quality of services is multidimensional. There are different methods for determining the patients' expectations and service quality but among all of them SERVQUAL model, developed by Parasuraman et al is one of the best models for assessment of patients' expectations, 
perceptions and quality of the services. SERVQUAL is based on the idea that the quality is a subjective evaluation of the customer, as the service is not a physical item but an experience. ${ }^{1}$

Earlier, service quality was measured by difference between consumer perception and expectation on the basis of ten dimensions which includes; reliability, tangibility, communication, security, credibility, competence, understanding, access, understanding/knowing customers, responsiveness. Further this model was refined by parasuraman, berry and service quality can be measured on the basis of five dimensions; reliability, tangible, responsiveness, assurance and empathy and these five dimensions were further assessed by 22 items. $^{2}$

In India few studies have been done regarding quality of health care services and patient satisfaction but in West Bengal there is dearth of knowledge regarding patient satisfaction and quality of health service inrural hospital. ${ }^{3,4,6}$ Government health sector in West Bengal is the main source of health service among the people. With this background this study was conducted to measure the patient satisfaction and patients' perception and also the gap between expectation and perception regarding some important aspect of hospital services to identify the aspects of health facilities where we can improve.

\section{METHODS}

The present study was a cross sectional type of observational study done among patients of out-patient department (OPD) and in patient department of Chittaranjan Rural Hospital, Bhatar, Burdwan, West Bengal, during 15/09/15-15/12/15.

\section{Inclusion criterion}

- Patient admitted in the hospital for more than 24 hours (in case of indoor patient).

- $\quad$ Patients above the age of 18 years.

\section{Exclusion criterion}

- OPD patients requiringadmission.

- Patients who were referred from this hospital.

- $\quad$ Those who were very sick.

Sample size for OPD was calculated by using formula $\mathrm{z}^{2} \mathrm{pq} / \mathrm{l}^{2}$, where $\mathrm{z}=1.96$ (95\% confidence level), $\mathrm{p}=50 \%$ (percentages of patient satisfaction), $q=1-p, l=15 \%$ (relative precision) and considering the design effect 2, estimated sample size was $(171 \times 2=) 342$. Consecutive sampling was done to attain the required sample size. For IPD complete enumeration of discharged patients was done during the study period and it came out to be 175. Modified SERVEQUAL questionnaire was used to assess patients' satisfaction. ${ }^{1}$ For translation retranslation validity the questionnaire was initially translated from English to Bengali and then back- translated to English from Bengali. Then, prior to data collection the questionnaire was piloted through interviews with a sample of 15 patients. The corrections mainly concerned the phrasing of the questions in Bengali.

After taking written consent and explaining the purpose of the study, the questionnaire was administered to the study subjects. For those patients who were unable to fill up the questionnaire, it was filled up with the help of the investigator or his or her close relative. Patients were assured about full confidentiality and anonymity of the survey. Statistical analysis was done by descriptive and inferential statistics.

\section{RESULTS}

A five-point Likert scale was used, ranging from strongly disagree (1) to strongly agree (5) to assess the level of patients' expectation and perception of service quality. The surveyed questionnaires were collected and coded in MS Excel database and analysed by using the SPSS statistical package, version 20.0. Descriptive statistics were performed on the socio-demographic data. The coefficient alpha values were observed to be consistently high, ranging from 0.707 to 0.760 indicating high internal consistency among items within the SERVQUAL instrument.

\section{Result of outpatient department}

Out-patient department

Among 350 patients from out-patient department $52.57 \%$ were male and $65.14 \%$ were Hindu. $18.57 \%$ were illiterate. Among the male patients $50 \%$ were unskilled worker and $46.4 \%$ of female were homemaker. As per modified BG Prasad scale $64.57 \%$ people fall under socioeconomic class $\mathrm{V}$.

The Expectation values were consistently high for all the items. The highest expectation value was observed against the item no. 7 (Getting things right the first time) and the lowest expectation score was for item no.4 (Visually appealing materials). In the similar way highest and lowest perception score was found against the item no. 19 (Convenient working hours) and 20 (Readiness for personal attention) (Table 1 and 3 ).

Service quality gaps (E-P) have been illustrated in Tables 1. It is showing that quality gaps exist along all 22 items of the survey instrument except item no. 19. Gap across all the item is statistically significant at $<0.001$ value except item no.17 (Adequate knowledge) and 19. It was found that highest service quality gap exist against the question no. 7 (Gets things right the first time). 
As regard to SERVQUAL important score it was found that Reliability dimension (24.54) is the most priority area and Empathy dimension (15.50) is the least priority area among all five SERVQUAL dimension (Table 2).

Table 1: Item score analysis for expectations and perceptions (mean scores for patients' expectations, perceptions and quality gaps and $p$ value).

\begin{tabular}{|c|c|c|c|c|}
\hline Items & $\begin{array}{l}\text { Expectation(e) } \\
\text { Mean } \pm \text { sd }\end{array}$ & $\begin{array}{l}\text { Perception(p) Mean } \\
\pm \text { sd }\end{array}$ & $\begin{array}{l}\text { Gap } \\
(p-e)\end{array}$ & $\begin{array}{l}\text { P value } \\
\text { Sig.(two tail) }\end{array}$ \\
\hline \multicolumn{5}{|l|}{ Tangibles } \\
\hline Modern equipment & $3.75 \pm 1.159$ & $2.53 \pm 1.062$ & 1.22 & .000 \\
\hline Physical facilities & $3.69 \pm 1.098$ & $2.61 \pm 1.040$ & 1.08 & .000 \\
\hline Clean and hygienic appearance & $3.95 \pm .906$ & $3.41 \pm 1.173$ & 0.54 & .000 \\
\hline Visually appealing materials & $3.51 \pm 1.037$ & $2.63 \pm .932$ & 0.88 & .000 \\
\hline Average & 3.73 & 2.80 & 0.93 & \\
\hline \multicolumn{5}{|l|}{ Reliability } \\
\hline Full fill promises within time & $4.38 \pm .716$ & $3.35 \pm 1.112$ & 1.03 & .000 \\
\hline Sympathetic attendance to patients & $4.41 \pm .644$ & $3.40 \pm 1.084$ & 1.01 & .000 \\
\hline Gets things right the first time & $4.78 \pm .453$ & $2.98 \pm 1.226$ & 1.80 & .000 \\
\hline Provides its services at the time & $4.27 \pm .778$ & $3.38 \pm 1.203$ & 0.89 & .000 \\
\hline Accurate records & $3.82 \pm .870$ & $3.31 \pm .935$ & 0.51 & .000 \\
\hline Average & 4.33 & 3.28 & 1.05 & \\
\hline \multicolumn{5}{|l|}{ Responsiveness } \\
\hline $\begin{array}{l}\text { Information before performing any } \\
\text { services/procedure }\end{array}$ & $3.75 \pm .977$ & $2.83 \pm .960$ & 0.92 & .000 \\
\hline Prompt service & $4.69 \pm .497$ & $3.15 \pm 1.325$ & 1.54 & .000 \\
\hline Staff always willing to help & $4.43 \pm .693$ & $3.50 \pm 1.109$ & 0.93 & .000 \\
\hline Prompt response to any request & $4.75 \pm .474$ & $3.37 \pm 1.288$ & 1.38 & .000 \\
\hline Average & 4.40 & 3.21 & 1.19 & \\
\hline \multicolumn{5}{|l|}{ Assurance } \\
\hline Can trust staff & $3.99 \pm .845$ & $3.09 \pm 1.203$ & 0.90 & .000 \\
\hline Feel safe & $4.14 \pm .789$ & $3.35 \pm 1.065$ & 0.79 & .000 \\
\hline $\begin{array}{l}\text { Consistently courteous by hospital } \\
\text { personnel's }\end{array}$ & $4.60 \pm .610$ & $3.21 \pm .1 .325$ & 1.39 & .000 \\
\hline Adequate knowledge & $4.10 \pm .837$ & $3.97 \pm .984$ & 0.13 & .071 \\
\hline Average & 4.20 & 3.40 & 0.80 & \\
\hline \multicolumn{5}{|l|}{ Empathy } \\
\hline Individual attention to patients & $3.80 \pm 1.026$ & $2.59 \pm 1.039$ & 1.21 & .000 \\
\hline Convenient working hours & $4.35 \pm .708$ & $4.42 \pm .814$ & -0.07 & .172 \\
\hline Readiness for personal attention & $3.63 \pm 1.220$ & $1.97 \pm .960$ & 1.66 & .000 \\
\hline $\begin{array}{l}\text { Staff have best interests of the patients in their } \\
\text { heart }\end{array}$ & $3.96 \pm 1.041$ & $3.04 \pm 1.167$ & 0.92 & .000 \\
\hline Staff aware of the needs of the patients & $4.31 \pm .723$ & $2.88 \pm 1.160$ & 1.43 & .000 \\
\hline Average & 4.01 & 2.98 & 1.06 & \\
\hline Total average expectation & 4.13 & 3.13 & 1.00 & \\
\hline
\end{tabular}

Table 2: SERVQUAL importance scores.

\section{SER VQUAL Dimension}

Average tangible

Average reliability

Average responsiveness

Average assurance

Average empathy

TOTAL
Importance weight

15.87

24.54

23.84

20.10

15.50

$\approx 100$ 
Table 3: Extreme values of expectation, perception and expectations perceptions gap.

The five statements with the highest expectation scores

\section{Items}

7. Gets things right the first time

13. Prompt response to any request

11. Prompt service

16. Consistently courteous by hospital personnel's

12. Staff always willing to help

The five statements with the lowest expectation scores

Items

4. Visually appealing materials

20. Readiness for personal attention

2. Physical facilities

1,10 . Modern equipment, Information before performing any services/procedure

18. Individual attention to patients

The five statements with the highest perception scores

Items

19. Convenient working hours

17. Adequate knowledge

12. Staff always willing to help

3. Clean and hygienic appearance

6.Sympathetic attendance to patients

The five statements with the lowest perception scores

Items

20. Readiness for personal attention

1. Modern equipment

18. Individual attention to patients

2. Physical facilities

3. Clean and hygienic appearance

The five statements with the highest quality gap scores

Items

7. Gets things right the first time

20. Readiness for personal attention

11. Prompt service

22. Staff aware of the needs of the patients

16. Consistently courteous by hospital personnel's
Mean score

4.78

4.75

4.69

4.60

4.43

Mean score

3.51

3.63

3.69

3.75

3.80

Mean score

4.42

3.97

3.50

3.41

3.40

Mean score

1.97

2.53

2.59

2.61

2.63

Mean score

1.80

1.66

1.54

1.43

1.39

\section{In-patient department}

On the other hand among 309 patients from in patient department $43.7 \%$ were male and $65.04 \%$ were hindu. $19.41 \%$ were illiterate. Among the male patients $51.9 \%$ were unskilled worker and $48.9 \%$ of female were homemaker. As per modified BG Prasad scale $71.2 \%$ people fall under socioeconomic scale class $\mathrm{V}$.

The expectation values were consistently high for all the items same like out-patient department. The highest expectation value was observed against the item no. 7 (Gets things right the first time) and lowest expectation score belongs to item no.4 (Visually appealing materials).
In the similar way highest and lowest perception score was found against the item no. 19 (Convenient working hours) and 20 (Readiness for personal attention) (Table 4 and 6).

As can be seen from Table 4, quality gaps exist along all 22 item of the survey instrument except item no. 19. Gap across all the item is statistically significant at $<0.001$ value except item no.17 (Adequate knowledge) and 19.

It is found that highest service quality gap existagainst the question no. 20 (Readiness for personal attention) (Table 6). 
As regard to SERVQUAL important score it was found that Reliability dimension (26.37) is the most priority and
Tangible dimension (12.65) is the least priority area among all five SERVQUAL dimension (Table 5).

Table 4: Item score analysis for expectations and perceptions (mean scores for patients' expectations, perceptions and quality gaps and $p$ value).

\begin{tabular}{|c|c|c|c|c|}
\hline Items & $\begin{array}{l}\text { Expectation }(\mathbf{E}) \\
\text { Mean } \pm \text { SD }\end{array}$ & $\begin{array}{l}\text { Perception }(\mathbf{P}) \\
\text { Mean } \pm \text { SD }\end{array}$ & $\begin{array}{l}\text { Gap } \\
(\text { P-E) }\end{array}$ & $\begin{array}{l}\text { P value Sig.( } 2 \\
\text { tailed) }\end{array}$ \\
\hline \multicolumn{5}{|l|}{ Tangibles } \\
\hline Modern equipment & $4.21 \pm .845$ & $2.44 \pm .970$ & 1.77 & .000 \\
\hline Physical facilities & $3.67 \pm 1.114$ & $2.60 \pm 1.035$ & 1.07 & .000 \\
\hline Clean and hygienic appearance & $3.94 \pm .906$ & $3.41 \pm 1.169$ & 0.53 & .000 \\
\hline Visually appealing materials & $3.50 \pm 1.024$ & $2.50 \pm .859$ & 1.00 & .000 \\
\hline Average & 3.83 & 2.74 & 1.09 & \\
\hline \multicolumn{5}{|l|}{ Reliability } \\
\hline Full fill promises within time & $4.37 \pm .717$ & $3.33 \pm 1.111$ & 1.04 & .000 \\
\hline Sympathetic attendance to patients & $4.62 \pm .492$ & $3.29 \pm 1.040$ & 1.33 & .000 \\
\hline Gets things right the first time & $4.81 \pm .404$ & $2.92 \pm 1.180$ & 1.89 & .000 \\
\hline provides its services at the time & $4.26 \pm .779$ & $3.52 \pm 1.150$ & 0.74 & .000 \\
\hline Accurate records & $3.81 \pm .872$ & $3.31 \pm .940$ & 0.50 & .000 \\
\hline Average & 4.37 & 3.27 & 1.10 & \\
\hline \multicolumn{5}{|l|}{ Responsiveness } \\
\hline $\begin{array}{l}\text { Information before performing any } \\
\text { services/procedure }\end{array}$ & $3.75 \pm .973$ & $3.23 \pm 1.012$ & 0.52 & .000 \\
\hline prompt service & $4.73 \pm .458$ & $2.85 \pm 1.190$ & 1.88 & .000 \\
\hline Staff always willing to help & 4.50 .606 & $3.38 \pm 1.124$ & 1.12 & .000 \\
\hline Prompt response to any request & $4.77 \pm .453$ & $3.54 \pm 1.194$ & 1.23 & .000 \\
\hline Average & 4.44 & 3.25 & 1.19 & \\
\hline \multicolumn{5}{|l|}{ Assurance } \\
\hline Can trust staff & $4.10 \pm .816$ & $2.95 \pm 1.065$ & 1.15 & .000 \\
\hline Feel safe & $4.25 \pm .725$ & $3.27 \pm 1.058$ & 0.98 & .000 \\
\hline $\begin{array}{l}\text { Consistently courteous by hospital } \\
\text { personnel's }\end{array}$ & $4.63 \pm .546$ & $3.17 \pm 1.298$ & 1.46 & .000 \\
\hline Adequate knowledge & $4.23 \pm .743$ & $4.07 \pm .940$ & 0.16 & .035 \\
\hline Average & 4.30 & 3.37 & 0.94 & \\
\hline \multicolumn{5}{|l|}{ Empathy } \\
\hline Individual attention to patients & $3.91 \pm .937$ & $2.48 \pm .732$ & 1.43 & .000 \\
\hline Convenient working hours & $4.40 \pm .650$ & $4.41 \pm .815$ & -0.01 & .863 \\
\hline Readiness for personal attention & $4.02 \pm .901$ & $1.97 \pm .960$ & 2.05 & .000 \\
\hline $\begin{array}{l}\text { Staff have best interests of the } \\
\text { patients in their heart }\end{array}$ & $4.19 \pm .824$ & $2.91 \pm 1.085$ & 1.28 & .000 \\
\hline $\begin{array}{l}\text { Staff aware of the needs of the } \\
\text { patients }\end{array}$ & $4.21 \pm .795$ & $2.89 \pm 1.152$ & 1.32 & .000 \\
\hline Average & 4.15 & 2.93 & 1.22 & \\
\hline Total average expectation & 4.22 & 3.11 & 1.11 & \\
\hline
\end{tabular}

Table 5: SERVQUAL importance scores.

\section{SERVQUAL dimension}

Average Tangible

Average Reliability

Average Responsiveness

Average Assurance

Average Empathy

Total
Importance weight

12.65

26.37

24.87

19.79

16.32

$=100$ 
Table 6: Extreme values of expectation, perception and expectations perceptions gap.

The five statements with the highest expectation scores

\section{Items}

7. Gets things right the first time

Mean score

4.81

13. Prompt response to any request

11. prompt service

16. Consistently courteous by hospital personnel's

6. Sympathetic attendance to patients

The five statements with the lowest expectation scores

Items

4. Visually appealing materials

2. Physical facilities

9. Accurate records

18. Individual attention to patients

3. Clean and hygienic appearance

The five statements with the highest perception scores

Items

19. Convenient working hours

17. Adequate knowledge

13. Prompt response to any request

8. provides its services at the time

3. Clean and hygienic appearance

The five statements with the lowest perception scores

Items

20. Readiness for personal attention

1. Modern equipment

18. Individual attention to patients

4. Visually appealing materials

2. Physical facilities

The five statements with the highest quality gap scores

Items

20. Readiness for personal attention

7. Gets things right the first time

11. Prompt service

1. Modern equipment

16. Consistently courteous by hospital personnel's

\section{DISCUSSION}

In this study Expectation value was consistently high, and significant service quality gap persist for most of the items as well as among all the five domains similar to the study done by Col Avijit Chakraborty and Annamalai Solayappam et al. ${ }^{4,9}$ Among all domains highest quality gap score was against the domain empathy for in patient department similar to the study done by Asghar Zarei et al. ${ }^{1}$

According to this study highest expectation score were for item no 7 and 13 (Gets things right the first time and Prompt response to any request). Similar result also found in other studies. ${ }^{1,4}$
Highest perception score was against the item no 19 (Convenient working hours), but a study done by Dr, Mamta Brahmbhatt et al found that the lowest perception score was for the same. ${ }^{10}$ In this BPHC level hospital services are available for $24 \times 7$ hours with emergency services and in INDIA as per govt. rule no BPHC level hospital can deny any patients at any time of the day. Study done by Mamta Brahmbhatt et al included 5 private hospitals with 3 govt. hospital. Private hospital can mention a particular time for their services which a govt. hospital of BPHC level cannot. Probably due to these two causes findings of this study did not match with the study done by Mamta Brahmbhatt et al.

This study has focused on a very important aspect of our existing health system. In the present scenario when we regularly find that in spite of most of the facilities 
available, patients are willing to go directly in tertiary care hospital. This study helps policy makers, health care managers and administrators to plan conceptually in improving health care delivery system.

The analysis of this study highlights some areas where the hospital services are far away from the patients expectation and some other aspects where patients perception are very close to patient expectation. In all five dimensions expectation is always higher than patients' perception suggesting that there is a scope for improvement of service quality. Keeping in mind about the limitation of health delivery system, specially resource related, this study will guide to prioritize hospital services. As the quality of services is multidimensional and always very difficult to measure, this study supports to measure service quality and consequently monitor it systematically in order to improve quality of services or decrease the gap between patients expectation and perception as much as possible. Finally it should be kept in mind that service quality or patient perception and expectation cannot be fully measured by a questionnaire. A combined qualitative and quantitative research method in future will provide a better assessment of service quality of health care system.

\section{CONCLUSION}

This study measured service quality of a hospital in the context of patients' perceptions and expectations and identified some areas of improvement while catering health services. The findings can help the healthcare provider to plan conceptually in improving health care delivery systems.

\section{ACKNOWLEDGEMENTS}

We would like to thank all the study subjects, Dr. Sanghamitra Bhowmik (BMOH of Chittaranjan Rural Hospital, Bhatar, Burdwan) and Dr.Dilip kumar Das (Head of the department of Community Medicine, Burdwan Medical College and Hospital). We specially thank Deotima Saha (B.Sc nursing) for continuous help in every steps of this study.

Funding: No funding sources Conflict of interest: None declared
Ethical approval: The study was approved by the Institutional Ethics Committee

\section{REFERENCES}

1. Zarei A, Arab M, Froushani A, Rashidian A, Tabatabaei S. Service quality of private hospitals: The IranianPatients' perspective. BMC Health Serv Res. 2012;12:31.

2. Irfan S, Ijaz A, Farooq M. Patient satisfaction and service quality of public hospitals in Pakistan: an empirical assessment. MEJSR. 2012;6:870-7.

3. Qadri S, Pathak R, Singh M, Ahluwalia S, Saini S, Garg P. An assessment of patients satisfaction with services obtained from a tertiary care hospital in rural Haryana. Int J Collab Res Intern Med Public Heal. 2012;4(8):1524-37.

4. Chakravarty A. Evaluation of service quality of hospital outpatient department services. MJAFI 2011;67:221-4.

5. Eleonora K, GlaveliNiki P, Chrissoleon T. Health Care Quality in Greek NHS Hospitals: No one knows better than patients.

6. Kavitha R. A comparative study on patients' satisfaction in health care service. European Journal of Business and Management. 2012;4(13):156-9.

7. Iwaarden JV, Wiele TDV, Ball L, Millen R. Applying SERVQUAL to web sites: an exploratory study. Int. J. Qual. Reliability Manage. 2003;20:919 -35 .

8. Tavakol M, DennickR .Making sense of Cronbach's alpha. International Journal of Medical Education. 2011;2:53-5.

9. Solayappam A, Jayakrishna J, Velmani S. Quality measurement for hospital services. IPEDR. 2011;12. IACSIT Press, Singapore

10. Brahmbhatt $\mathrm{M}$, Baser N, Joshi N. Adapting the servqual scale to hospital services: an empirical investigation of patients' perceptions of service quality. Int J Multidiscip Res. 2011;1(8):27-42.

Cite this article as: Naskar P, Naskar S, Roy S. Assessment of patient's satisfaction regarding the service quality of a rural hospital of Burdwan district, West Bengal, India. Int J Community Med Public Health 2016:3:2222-8. 